\title{
The technique matters, it's just not clear how
}

\author{
Ryan R. Davies, MD
}

\author{
From the Nemours Cardiac Center, A. I. duPont Hospital for Children, Wilmington, Del; and Thomas Jefferson \\ University, Philadelphia, Pa. \\ Disclosures: Author has nothing to disclose with regard to commercial support. \\ Received for publication March 28, 2016; accepted for publication March 30, 2016. \\ Address for reprints: Ryan R. Davies, MD, Nemours Cardiac Center, A. I. duPont Hospital for Children, \\ 1600 Rockland Rd, Wilmington, DE 19803 (E-mail: rdavies@nemours.org). \\ J Thorac Cardiovasc Surg 2016;152:480-1 \\ $0022-5223 / \$ 36.00$ \\ Copyright $(2) 2016$ by The American Association for Thoracic Surgery \\ http://dx.doi.org/10.1016/j.jtcvs.2016.03.066
}

Since Norwood's initial description of his eponymous procedure, ${ }^{1}$ the importance of unobstructed systemic outflow to long-term ventricular function has been well recognized. With the goal of minimizing any obstruction within the reconstructed aortic arch, there has been a traditional focus - in both research analyses and technical modifications of the reconstruction - on minimizing or eliminating the risk of recoarctation. ${ }^{2}$ The study by Plummer and colleagues ${ }^{3}$ in the current issue of The Journal moves beyond the relatively simple assessment of aortic arch pressure gradients and the need for reinterventions to evaluate the anatomy and physiology of the aorta and aortic arch in patients after the Norwood procedure. This is important, because even in the absence of significant echocardiographic flow acceleration or a clear recoarctation, alterations in the aortic response to ventricular ejection may have important consequences on long-term ventricular function.

Plummer and colleagues ${ }^{3}$ have identified several potentially maladaptive responses in the aortas of patients after the Norwood procedure. These include increased aortic stiffness, aortic dilatation, and a high frequency of abnormal arch geometries. Some of these have been identified previously, ${ }^{4-6}$ but not in a multi-institutional study. Surprisingly, Plummer and colleagues ${ }^{3}$ were unable to correlate any of these maladaptive responses with alterations in right ventricular function. Given previous studies in patients after the Norwood operation correlating aortic stiffness with magnetic resonance imaging measurements of ventricular function, ${ }^{6}$ the lack of correlation here is more likely to be the result of shorter follow-up and the limitations of echocardiography in evaluating the right ventricle than a true lack of effect. Similarly, whether the association between increased aortic size and the use of a right ventricle-pulmonary artery conduit is real or the result of the use of 2-dimensional imaging with only the lateral angiographic projections included in the analysis is unclear and bears further study.

Perhaps the most important finding, however, is the substantial variation among centers in aortic arch anatomy after the Norwood procedure. The incidence of normal arch anatomy varied among centers, from a low of $17 \%$

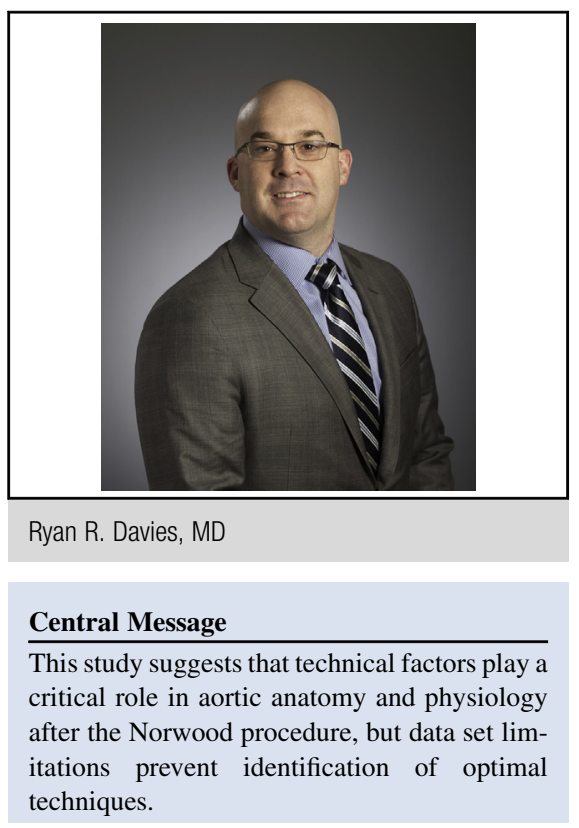

See Article page 471 .

to a high of $57 \%$. This suggests that technical factors may play a key role in determining aortic arch anatomy, with a potentially critical impact on long-term aortic physiology and ventricular function. Unfortunately, because of the limitations of the Single Ventricle Reconstruction trial data, no information is provided on the technical aspects of the repair associated with improved outcomes (either geometric or physiologic). The data tantalizingly suggest that some techniques may be better than others but cannot provide any guidance as to which those might be.

This study joins an increasing body of literature that recognizes the impact that aortic wall properties, including compliance and elasticity, have on ventricular dynamics. ${ }^{4-6}$ With a large, prospective, multi-institutional dataset, Plummer and colleagues ${ }^{3}$ have shown that importantand potentially deleterious-alterations in aortic structure and function occur after the Norwood procedure. The limitations of the data set limit the conclusions. But the data reinforce the importance of surgical technique in this complex procedure and encourage future multiinstitutional studies to identify which technical factors optimize aortic anatomy and minimize the maladaptive aortic response to arch reconstruction.

\section{References}

1. Norwood WI, Lang P, Hansen DD. Physiologic repair of aortic atresia-hypoplastic left heart syndrome. N Engl J Med. 1983;308:23-6. 
2. Lamers LJ, Frommelt PC, Mussatto KA, Jaquiss RDB, Mitchell ME, Tweddell JS. Coarctectomy combined with an interdigitating arch reconstruction results in a lower incidence of recurrent arch obstruction after the Norwood procedure than coarctectomy alone. J Thorac Cardiovasc Surg. 2012;143:1098-102.

3. Plummer ST, Hornik CP, Baker H, Fleming GA, Foerster S, Ferguson ME, et al. Maladaptive aortic properties after the Norwood procedure: an angiographic analysis of the Pediatric Heart Network Single Ventricle Reconstruction Trial. J Thorac Cardiovasc Surg. 2016;152:471-9.e3.
4. Cardis BM, Fyfe DA, Mahle WT. Elastic properties of the reconstructed aorta in hypoplastic left heart syndrome. Ann Thorac Surg. 2006;81:988-91.

5. Voges I, Jerosch-Herold M, Wegner P, Hart C, Gabbert D, Al Bulushi A, et al Frequent dilatation of the descending aorta in children with hypoplastic left heart syndrome relates to decreased aortic arch elasticity. JAm Heart Assoc. 2015;4:e002107. 6. Voges I, Jerosch-Herold M, Hedderich J, Westphal C, Hart C, Helle M, et al Maladaptive aortic properties in children after palliation of hypoplastic left heart syndrome assessed by cardiovascular magnetic resonance imaging. Circulation. 2010;122:1068-76 